\title{
The Influence of Music Education on the Value Orientations of Teenagers
}

\author{
Xiaoying Guo \\ Department of music, Nanchang Normal University
}

Keywords: Education; Music education; Value; Value orientation.

\begin{abstract}
Music education is an indispensable part of current quality education system. National guiding principle for education requires comprehensive development in moral, intelligence, sports, aesthetics and labor, among which basic way of implementation of aesthetic education is music education. From the integral perspective of imparting knowledge and educating people, music education helps improve students' individual quality, helps students' satisfaction of needs and helps students' development of personality. Based on the unique function of music education and characteristics of psychological development of teenagers, this paper discusses the important meaning of music education in optimizing teenagers' psychological quality and improving their balanced development of body and soul, carries out rational introspection and criticism on conditions and problems in China's existing education, explores what should education do and based on and proposes that the value orientation of education should aim to promote people's quality harmonious development, perfecting personality and respecting people's subject value. From the angle of educational value, it probes into and reviews current status and problems of existing education system in China. This paper proposes to establish "people-oriented" value orientation in process of talent cultivation and conform to the nature and era characteristics of contemporary education by taking talent cultivation property and transcendence of education as entry point.
\end{abstract}

\section{Brief Introduction}

Music is an art good at manifesting and stimulating emotions. Appreciation is rich in fantasy and enables people to surmount everything, thus the process of music appreciation is the process of emotional experience. With euphemistic melody, smooth wave and delicate feelings, Jasmine is widely spread around China and even the world and becomes a representative element in Chinese culture. Ode to the Motherland in Olympics is an inspiring song that manifests lofty sentiments and faith of Chinese people. In the magnificent Yellow River Cantata, the author uses words with full emotion to reveal the great spirit and invincible power of Chinese nation, eulogize the great motherland with long history, show Chinese people's indomitable will to fight and spirit to struggle, bitterly attack inhumanity of invaders and reveal the magnificent scene in which the masses defend the country and resist aggression.

Researches show that fast and pleasant music is able to remove muscle fatigue. Fast change of rhythm enables the speed of people's pulse and breath become fast; sad melody slows down the pulse rate, while lively music has the opposite effect. The improvement of brain and the whole neurological function keeps people in high spirit and in physical and mental pleasure. In the meantime, beautiful melody can pacify mood, concentrate people, strengthen delight of life and even accelerate recovery of physical and psychological health in some aspects. It can be seen that music has great impact on people's spirit and emotions. 
The imperfect education system of China causes the status of music education in the whole educational structure to become specialty teaching, and most students are rejected by "music". Such teaching status directly violates the fundamental objective of China in carrying out compulsory education and fails to let every student have equal opportunity to receive education. Furthermore, China's education system attaches importance to traditional cultural education, causing students' mode of receiving education to become single and hindering formation of students' personality. Music education becomes formalized. Although many students know some music nouns and terms, they don't know the meaning behind those words, let alone application. Under such educational circumstance, it will be difficult to give full play to characteristics of music education, students become less interested in learning music and it eventually results in the phenomenon in which many students love music, but they hate music lesson. Therefore, to solve the current status of China's music education, educators have to lay emphasis on music education, truly cater to students' needs, turn music lesson into real music education and truly promote students' music accomplishment.

This paper introduces multiple intelligence theory and combination of this theory and subject characteristics of music education. Application of music, the non-linguistic aesthetic experience activity, to achieve the goal in developing teenagers' intelligence not only has strong applicability but also has far-reaching effect. It is not only conducive to cultivating students' music taste, but also conducive to establishing accurate value of music education. In addition, it also plays an important role in purification of students' heart and formation of healthy morality, outlook on life and world outlook.

It is hoped that this study has preliminary structural construction of ideal value orientation of teachers. As for value orientation of music education, it has to critically absorb the essence in value orientation of traditional education as it caters to new criteria of teaching value. Teachers should be able to recognize the nature of education, experience the real look of teaching and master right value orientation in teaching process to enable music education to truly exert positive influence on comprehensive and harmonious development of students' mind and body.

\section{Music Education's Help in Growth of Teenagers}

Bioscience's study of function area of human brain shows that the right hemisphere and the left hemisphere of brain work clearly are clear in division of labor and mutually link to each other. The whole work pattern of brain is discrete and uniform as well. Relatively speaking, the left cerebral hemisphere is good at abstract thinking such as logic and inference and is generally regarded as mathematical axis; while the right cerebral hemisphere is good at intuitive thinking including imago and imagination and is defined as emotion axis. In view of the early basic educational pattern taking ability obtaining as objective, students' understanding of things is based on left hemisphere thinking model under many circumstances, namely the "causal relationship". Traditional educational pattern results in pure faith in symbolism. It is stiff and mechanical, strictly constraints students' thinking and limits their imagination. However, in bioscience, the information capacity the right cerebral hemisphere possesses is one million times that of the left cerebral hemisphere. Just from the perspective of creation and invention, the effect of intuitive thinking is definitely as good as abstract thinking. If a person wants to develop comprehensively, "complex brain education" is absolutely necessary. Hence, development of intuitive thinking of the right cerebral hemisphere is a problem to be faced and solved in the quality education process. 
Music education plays an indispensible and particular role in cultivating people's comprehensive development of quality and is an important way to realize people's harmonious development of all aspects. It helps people feel the connotation of music when they learn music knowledge and master music skills. "The Spring Snow and the Countrymen" cultivate and purify people's aesthetics, thoughts and emotions and heart and help them develop comprehensively. In the aspect of future quality education and people's comprehensive development, music education plays a decisive role and has huge potential.

Education of any discipline not just aims to impart knowledge and skill. The most important objective of education is to achieve "comprehensive internalization" of students' quality, so does music education. Music becomes a special art because of its abstraction and expression of human's feelings. It has profound, accurate, delicate and direct characteristics in expression of feelings. Music is able to achieve high unity, mutual penetration and integration of reason and emotion. Song and emotion are able to move people. By virtue of its huge infection, music can let people feel the perfect and true state in the depth of their souls and purify their souls, which are beyond comparison to other disciplines. Heart moves with emotions. Listeners' emotion changes and thinking of brain becomes active with fluctuation of music rhythm. As the imagination is mobilized, people's creativity will be inspired. Innovation ability is valued in current inspection on talent quality. Due to distance of music in time and space, it plays a unique role in cultivation of creativity. With further promotion of music education, transition from simple auditory thinking to complex imaginal thinking and cultivation of people's imagination and creativity become possible. At the same time, people's sociability and adaptability are also exercised and improved correspondingly.

The philosopher Plato once said in The Republic, "music education is a top priority among multiple educations. The key is that music rhythm and tune can immerse into the deepest heart. Appropriate music education will turn into the most powerful force that infiltrates the heart. Heart becomes beautiful because of beauty, while people who receive music education will appreciate beautiful things in life in turn, making them become nutrients nourishing the heart and helping their own personality become noble." Liszt said "music is the emotion and flame that directly refresh the bottom of heart without help of any external force. It is the air inhaled from mouth and blood circulated in blood vessel of life." Music enables people to achieve lofty state in morality, sentiment, consciousness and concept through auditory sense and the imperceptible manner. For instance, the theme of Traumerei of Schumann is very simple. It manifests the author's pursuit of natural and pure beauty of childhood and is filled with romantic and dreamlike rhythm and is thought-provoking. Skilled technique romanticism brings us into a gentle and fascinating dreamlike state. Touching lyricism, fluctuated rhythm and euphemistical style lead people to a light and wispy dreamlike world. The process of appreciating this song is a process to improve listener himself. Edified by music, people's distracting thoughts are removed and heart purified.

\section{Several Aspects that Affect the Value Orientation of Teenagers}

Teenagers' having healthy mind and body is mainly reflected on six aspects: healthy physique, normal recognition, mature emotion, sound and healthy personality, stable and rational behavior and harmonious social relation. In addition to this, healthy mind and body also involve moral quality, behavior, emotion and recognition, etc.

The premise of mental healthy of teenagers is that they have healthy physique. Healthy body can not only affect physiological aspect in teenagers' growing process, but also affect psychological 
aspect of their growth. If a person has health problem, his physiology will have certain change, thus leading to corresponding fluctuation in his mental and emotional aspects. Likewise, if a person has unstable mentality and emotion, he will also have corresponding reaction in physiology. Hence, the prerequisite to keep well-developed both in mind and body is to own a good psychological state.

Teenagers lack possessiveness and their life experience is relatively single. Therefore, they will find it difficult to master their own social life under complicated social, cultural and political environment. A good social living environment is able to promote healthy growth of teenagers. On the contrary, undesirable social environment will severely hinder teenagers' mental and physical growth and even result in persistent disoperation. There are several harmful social factors that harm teenagers' souls:

First is the complexity and ugliness in social environment. The complicated social environment is filled with multiple harmful factors including money, beauty and corruption, etc. These factors easily give rise to deviation of teenagers' outlook on life, value and world outlook and even having negative final conclusion of social life.

Second is the harmful culture in internet cyberspace. With the development of science and technology, internet penetrates into people's production and living, but harmful culture in internet cyberspace also plays a negative role in development of human beings. For example, violent games and obscene contents on internet are likely to directly or indirectly lead to teenagers' fault recognition of sexual morality and violence, being tempted and eventually becoming criminals.

Third is the negative element in community environment. Community environment is able to shape teenagers' conduct, moral ideas and behavior to a great extent. A good community environment can promote teenagers' healthy growth, but undesirable community environment will cause teenagers who have no experience of life to make detours on the path of growth. Positive element in community environment will exert adverse effect on teenagers' growth.

Fourth are various pressures from life. Teenagers have weak psychological enduring capacity, thus they will have difficulty in enduring various pressures in life, e.g. entering high school, employment and love relationship, etc. Teenagers' failure relieve the pressure well will easily cause psychological shadow and even physiological illness.

Family is the initial environment in people's life. People have lived and grown up in family as a family member since they were separated from parent body. Hence, people's life is attached to family, and family plays an important role in people's growth and exerts long-term and profound influence.

Growing process of teenagers is a process of continuous imitation and learning. Through study, teenagers gradually establish outlook on life and values and form a relatively complete system of behavior. Therefore, the learning process at school will have greater impact than family, direct impact than the society and more in-depth impact on teenagers' growth. School education not only refers to teaching process of book learning, but also refers to specific practice education based on social factors. From the perspective of situation of school in current stage, school education still has certain development space for it should be equipped with factors such as practically, feasibility and perspectiveness to guide students' growth.

School education has to take three important factors into account: educators, educational ideas and educational environment. It exerts influence on students' mental and physical health. The first one is educator. Educator is the bridge that associates school and students and the executor to impart knowledge and ability to students, thus the level of educators' knowledge and quality and ability will 
have direct impact on students' mental and physical health. The second one is educational idea. Educational idea of school determines the way and pattern of running school and also determines the general direction of growth and development of the educated. For instance, teaching idea of a school is to teach students in accordance of their aptitude and create talents with individual difference, and it will make great efforts in excavating students' potential ability and enhancing students' learning passion and creativity during cultivation of students. The third one is the teaching environment. School should create a collective living and learning atmosphere based on strict system management, letting students experience amity, kindness and democracy of school.

\section{The Guiding Role of Higher Education in Formation of the Value Orientation of Music Teachers}

In terms of music education, foreign famous scholar said, "Music education not just faces musicians, but also faces all mankind." Teachers are an important resource to boost education modernization and an important guarantee to improve quality of compulsory education. The country with high level of teacher talent resource owns high quality citizens. In primary and secondary school education, music education has important impact on aesthetic enlightenment to primary and secondary school students. Hence, primary and secondary music education becomes an important carrier to implement quality education in the compulsory education stage. Strengthening primary and secondary music education requires construction of a team with high quality primary and secondary music teachers. At present, primary and secondary music teachers of China are mainly derived from music major or music department of normal colleges and schools with high music quality, but problems exist in aspects including educational ideas, educational methods and teaching ability of music teachers, which remain a large gap with requirement of quality education. Therefore, it has to strengthen the construction of team of primary and secondary music teachers and promote prosperity and development of music education enterprise.

Colleges and universities are major base in current training of music teachers in middle school in China. Under the new situation, current college music teaching has to change traditional concept by further making general and vague goal of training music team with music specialty become microscopic, professional and hierarchical; as far as educational object is concerned, college music education has to realize the transition from singing skills training to esthetic sentiment and shaping comprehensive development; as for educational technique, college music education of China has to pay more attention to applying material carrier to music teaching. In China's top teacher music education, most top teachers are unaware of the fact that there isn't much of a connection between the level of music skills and music accomplishment. Therefore, in music education, most top teachers focus on imparting music skills, thinking the improvement of music skills is equivalent to improvement of music accomplishment. In this way, it often neglects the connotation of music, leading to failure to promote students' music accomplishment through music education and complete consistency between educational orientation and national educational policy.

Teacher qualification system has important impact on quality of teachers in China. The state strictly selects talents conforming to teacher qualification through the system of qualification authentication of the teacher. Hence, teacher qualification system improves educational level and professional knowledge level of teachers to a certain extent. It can be said that the system of qualification authentication of the teacher is an important system to guarantee the level of national teacher teams. China has issued a series teacher qualification laws since the end of 1990s, among 
which the issuance of Measures for the Implementation of Regulations on the Qualifications of Teachers marked the uniform implementation of national teacher qualification system. The measures for the implementation point out that teachers of every subject can obtain the teacher qualification certificate through passing psychology, pedagogy and mandarin evaluation. In this way, it is impossible to assess the level of professional knowledge of music teachers in China through teacher qualification examination, and their music level remains unknown.

\section{Multicultural Music Education Facing the Future}

Through deriving the concept of "multicultural education" based on the angle of music, the "multicultural music education" is formed. Gary McPherson is the famous chairman of international music education who advocates this concept, elaborates the principles and methods and reiterates the four basic principles of "multicultural music education":

1. Given a broad view of the world, it has different kinds of music, and almost all different types of music have their respective guiding principles, background and styles, thus the independence of music should be respected;

2. To better understand music, it has to be based on specific background culture and social culture. To fully understand one certain culture, it also has to understand its music first. It must have a thorough analysis of background of the music culture in order to understand music thoroughly;

3. In terms of content, music education should possess extensive inclusiveness. Various music cultures and their background existing in the world are worthy of researching and studying. Music education has distinction between formal and informal. Music can be learned through different forms such as appreciation, creation and playing;

4. Teaching of global music should respect propagation process of all music and integrality of music.

From the perspective of evaluating teaching effect, music teaching evaluation has to consider specific conditions of all music students, and the evaluation should lay emphasis on roles of improvement, motivation and adjustment to further stimulate students' learning motivation. As the connection between students and teachers, evaluation can intensify communication between students and teachers. Hence, in order to achieve this goal, diversified methods of evaluation should be adopted to evaluate the effect of music classroom teaching. In the evaluation process, it should adopt multiple ways of evaluation including mutual evaluation between students and students, mutual evaluation between teachers and students and students' self-evaluation to further set up multidimensional evaluation systems, treat students' emotional state and association state as key points in evaluation and give up traditional evaluation which only focuses on cultivation of learning ability. Furthermore, understand students' longitudinal learning status through evaluation students in different periods of time. In other words, music teaching has to attach importance to longitudinal evaluation.

\section{Conclusions}

Music education has positive significance to teenagers' growth, which has had plenty of description in this paper. Appreciation of music is to use the form of music to express and manifest inner feelings, make them produce infinite love and passion to music, further become a person good at communicating with people and a person loves life and treasure life and form positive and optimistic attitude to affect their "three views". In fact, music education is able to effectively broaden teenagers' vision and offer necessary help and support for promoting their comprehensive 
accomplishment level. Furthermore, it is also an important part in current quality education. Therefore, primary and secondary schools should strengthen music education to provide vast teenagers with better music education and improve their music appreciation level.

General concept of campus music culture quoted in this paper is as follows: it is a systematic process in which campus members accept and inherit music values under specific environment to realize inheritance of music art according to stipulated music faith. In actual application process, it is able to deepen teachers and students' recognition of beauty on a psychological level, promote effective communication between teachers and students and provide necessary support and help for improvement of campus environment and establishment of campus image. Implementation of campus music culture education means that teachers complete inheritance and communication through combination of in-class and extracurricular music culture education and taking students as subject. This process is required to show students' principal status. Connotation of campus music culture is elegant and an important way to shape teachers and students' music accomplishment and cultivate their taste and better purify souls. Based on above-mentioned circumstances, we have to establish and complete a set of music educational ideas taking cultural inheritance as core contents, gain necessary music resources from the society, strengthen the construction of overall quality level of music teacher teams and further intensify the school-based construction of current music culture to offer objective help for teachers and students' common improvement and progress in the atmosphere of campus music culture. It is the primary starting point and foothold in developing primary and secondary music culture course and worthy of more attention and emphasis.

\section{References}

[1] Ye Lan. Caring for Life-Exploration of the Value Orientation of Contemporary Chinese School Education [M]. Beijing: Educational Science Publishing House, 2006.

[2] Li Changji. On Teaching Values [M]. Lanzhou: Gansu Education Publishing House, 2004.

[3] Liu Xudong. Study of the Value Orientation of Modern Courses [M]. Lanzhou: Gansu Education Publishing House, 2002.

[4] Wang Daojun, Wang Hanlan. Pedagogy [M]. Beijing: People's Education Press, 2001.

[5] Wang Hesheng. Study of the Value Orientation of Education [J]. Heilongjiang Social Sciences, 2007(2).

[6] Chu Hongqi. Discussion on Educational Value and the Concept of Educational Value [J]. Journal of Beijing Normal University, 1996(3).

[7] Zhou Hong. The Study of the Value Orientation of Education of Middle School Teachers under Pluralistic Educational Values Background [D]. Chonqing: Southwest China Normal University, 2010.

[8] Xie Xiaozhen. Test Theory of Educational Values of Quality Education [J]. Higher Education Exploration, 2001(1).

[9] Luo Ruguo, Wang Shanshan. Diagnosis of the Reality and Expected Pursuit of Teaching Value Orientation [J]. University Education Science, 2008 (6). 
[10] Wu Jie. The Study of Teaching Value Orientation under New Curriculum Concept [J] Journal of Suzhou University, 2005(6).

[11] Zhao Yanping. Exploration of Current Value Orientation of Chinese Education-Reflection based on Current Status of Education [J]. Contemporary Educational Science, 2003 (8) 